\title{
SSSC Annual Forum Features Progress Reports on MSE Study
}

The Solid State Sciences Committee (SSSC) of the National Academy of Sciences held its annual Spring Forum on March 12-13, 1987 in Washington, DC. The Forum was organized jointly by the SSSC and by the National Materials Advisory Board (NMAB) of the National Academy of Engineering (NAE). This year's Forum was devoted to a progress report on the Materials Science and Engineering (MSE) Study commissioned by the National Research Council for the Academies.

In his introductory remarks, SSSC chairman Al Narath pointed out that the MSE Study was conceived in response to a letter from [then] Congressman Don Fuqua, Chairman of the House Science and Technology Committee, to Frank Press and Robert White, presidents of the National Academies of Sciences and Engineering, respectively. It was two years ago that attendees at the SSSC Spring Forum in March 1985 discussed the content and format of a proposed MSE Study, essentially initiating the present Study. The concensus then and now was that "we need a much greater sense of unity within the field of materials science and engineering." Funding for the MSE Study has been provided by NSF, DOE, NASA, and DOD through DARPA, AFOSR, and ARO.

After additional welcoming remarks by NMAB chairman Bernard $\mathrm{H}$. Kear, the MSE Study chairs and panel chairs presented their progress reports. MSE Study cochair Praveen Chaudhari of IBM began by outlining the anticipated schedule for the remainder of 1987 . By May the Study chairs expect draft reports from each of the five panels. By August the first draft of the overall report should be completed, and by the end of 1987 a final 200-page document aimed at government and at the materials community should be available. After reviewing the charges to the five MSE Study panels and discussing the membership of each panel, Chaudhari asked the audience to contribute in two ways: first to assess the Study's progress by making specific criticisms and remarks as opposed to "motherhood statements"; and second, to consider ways the final report could be guaranteed to appropriately impact the policymaking bodies that affect the future of MSE in the United States.

Study cochair Prof. Merton Flemings of MIT then gave an overview of the Study, focusing on the factors common to all the panels. In particular, he proposed defining materials as "substances which man uses or wants to use for making things." $\mathrm{He}$ defined MSE as that area concerned with the interrelationships among four components - performance, properties, struc-

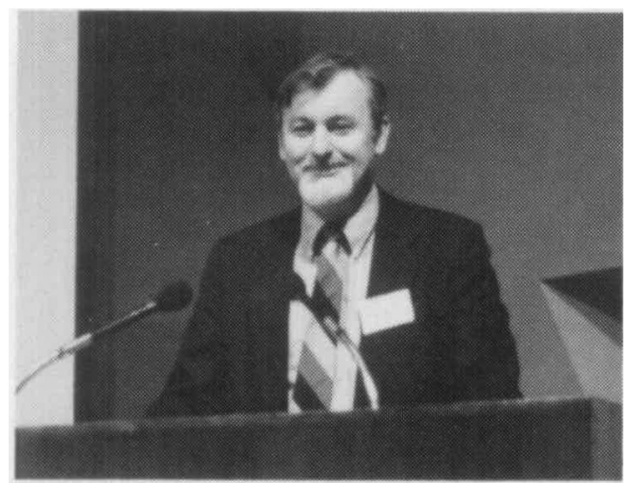

SSSC chairman A. Narath (AT\&T Bell Laboratories) welcomes participants to the SSSC Spring Forum.

ture, and synthesis/processing of materials. Using an illustration of these four components located at the vertices of a tetrahedron, he graphically demonstrated their interrelationship, indicating that the tetrahedron may become the logo of the MSE Study report. Flemings particularly cited the synthesis/processing vertex as the weakest of the four aspects of MSE in the United States and as the one requiring the most attention. In closing he noted that MSE is a crucial element of U.S. industrial competitiveness and that universities, industry, and government in various combinations have a critical role in strengthening MSE in the United States.

After the panel reports (described below) on the morning of March 12, the Forum participants attended one of five smaller sessions in order to critique the status of each panel. The results of these critiques were reported to the conclave the following morning by individuals chosen to summarize the previous day's discussions. The organizers of the MSE Study hope to incorporate suggestions and midcourse corrections, if needed, as the MSE Study proceeds to its final stages.

\section{Panel 1-Research Opportunities and Needs in MSE}

Representing Panel 1 was Prof. James Langer of the University of California at Santa Barbara. His panel, which is charged to assess the needs and opportunities for MSE, found that the intellectual vitality of research in MSE is good. A summary of findings so far by eight industry-related subpanels and one federal needs subpanel has shown advances in many areas. New materials states, phenomena, processes, technologies, tools and computational capabilities have been developed in recent times; and interactions with other fields such as biology, astrophysics, information science and geology are healthy. Among the advances Langer listed were quasicrystals, high $\mathrm{T}_{\mathrm{c}}$ superconductors, the quantum Hall effect, heavy fermions, chemical precursors for ceramics, diamond films, photonics, composite structural materials, atomic resolution microscopy, picosecond time scale measurements, ab initio calculations of structure, theoretical understanding of nonlinear phenomena, and advances in biomaterials.

Langer also pointed out that Panel 1 noticed a "weak coupling" between research and applications. He particularly mentioned gaps in the American steel industry, in dynamic random access memory production, in magnetic materials for information storage, in advanced ceramics, and in instrumentation for VLSI.

Four preliminary recommendations from Panel 1 cite the following needs:

- to encourage all institutions - government, university, industry, and federal laboratories alike - to treat MSE as a whole rather than subdivide it;

- to respond to weaknesses in materials synthesis, instrumentation research, and processing/manufacturing research;

- to devote special attention to U.S. strength in analysis and modeling; and

- to revitalize research in materials-based industries.

\section{Panel 2-Exploitation of MSE and}

\section{Technology for National Welfare}

Panel 2, whose charter involves the innovation and technology transfer process, was represented by Alan Chynoweth of Bell Communications Research. Chynoweth emphasized MSE's great leverage on the competitive posture of U.S. industry and its connection to the decline of U.S. industry since World War II. He noted that "the orient has delivered to the U.S. a 'commercial sputnik." He also noted, in the context of industry's shortsightedness in support of long-term research needs, that "the present tends to drive out the future."

Focusing on the innovation process, Chynoweth said that it requires (1) the direction of a known mission, purpose, and market; and (2) a critical mass of human, funding, and equipment resources as well as (3) agility or speed in transferring technology from research to application. $\mathrm{He}$ described a desirable industrial structure which has the appropriate corporate size, which can count on appropriate assured markets, which can couple technology to the market's needs, which avoids disaggregation into separate profit centers, and which possesses a vertically integrated structure as had been the case in the "now demolished Bell System."

Continued 


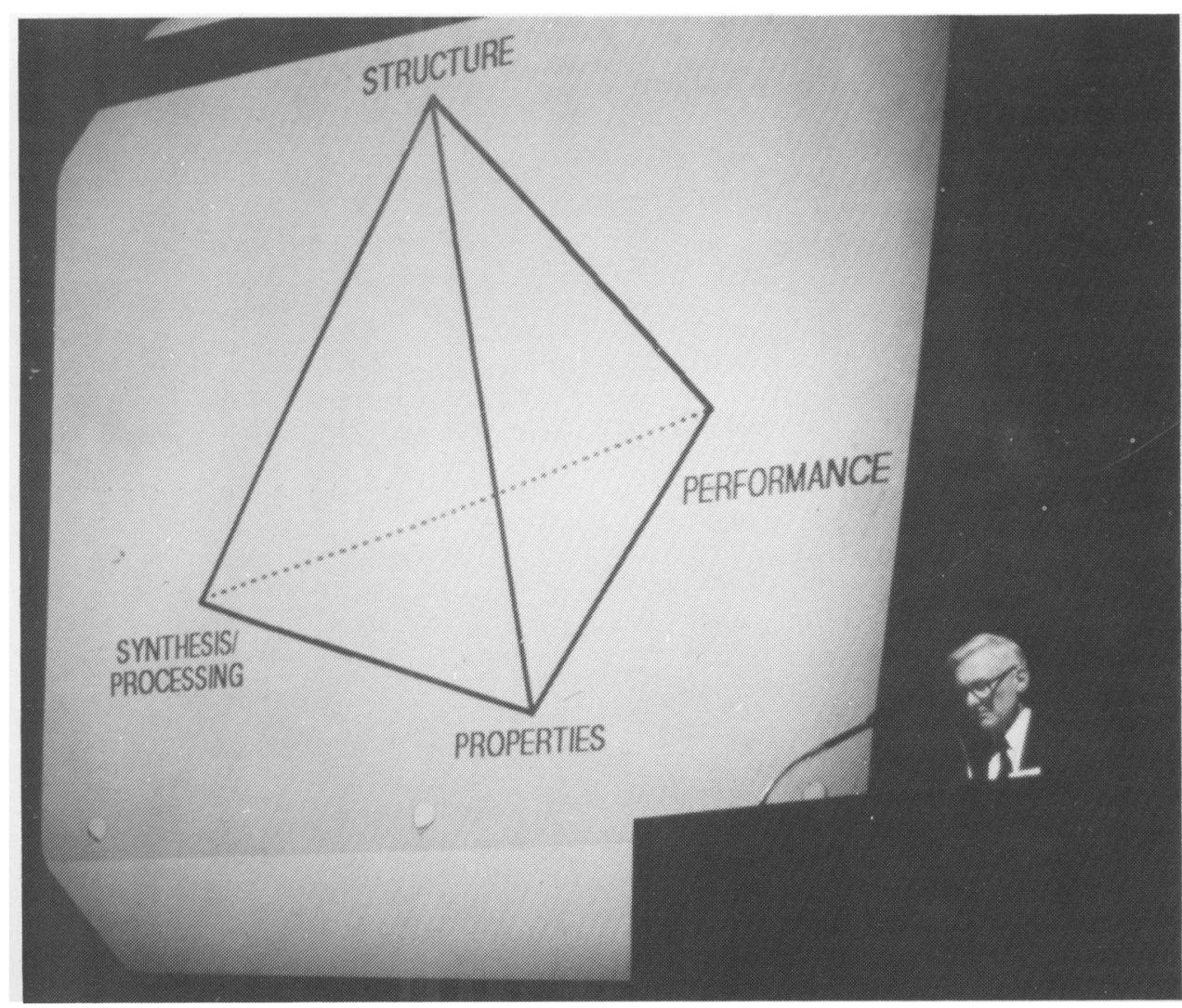

MSE Study cochair M. Flemings demonstrates the interrelationship of components of MSE using an illustration of the tetrahedron that might become the Study's logo.

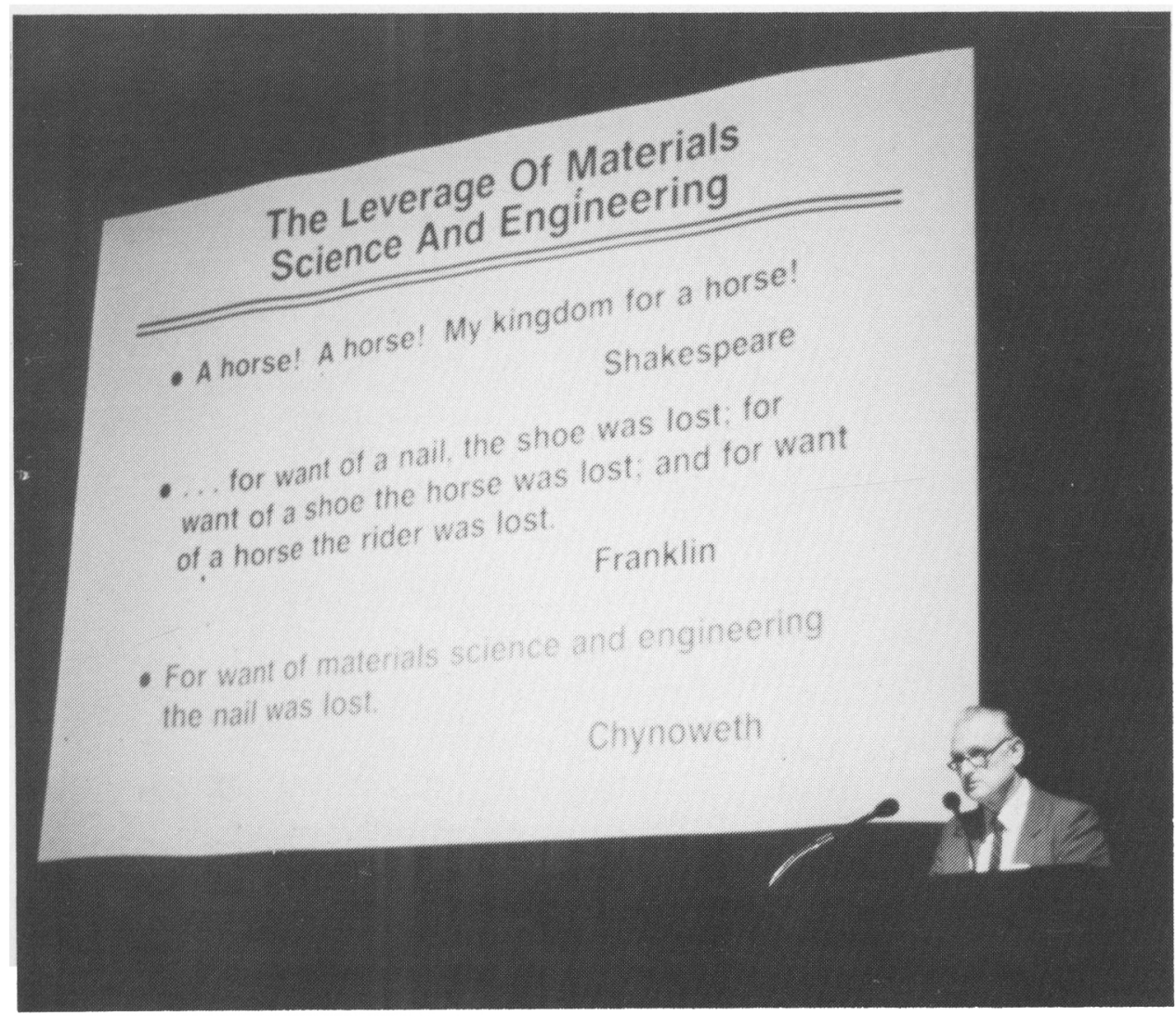

MSE Study Panel 2 chairman A. Chynoweth describes how MSE underlies many aspects of society.
Panel 2's three primary preliminary conclusions are that industrial consortia aimed at special needs of industry are needed, that effective technology transfer into and out of these consortia needs to be ensured, and that an increase in personnel in the various MSE disciplines is required. Chynoweth particularly emphasized "the need to improve the prestige of multidisciplinary applied science, especially manufacturing technology, on campuses to attract students."

Chynoweth explained that while the centripetal forces favoring consortia are largely economic, the centrifugal forces working against them are largely attitudinal. For technology transfer to succeed, he claimed, one must have personnel intermingling, matching "impedances" at the sending and receiving ends. One must have dollars for the interchange of people going in both directions. One must support "technology scanning and harvesting" to glean advances from the rest of the industrialized world. And, one must create a system of advanced communications to assist in networking among MSE researchers. Returning to his observation on industry's shortsightedness in its funding of research, Chynoweth decried "the tyranny of the quarterly report," saying "it is the job of business schools to re-educate corporate managers for farsightedness."

\section{Panel 3-International Cooperation and \\ Competition in MSE}

Lyle Schwartz of the National Bureau of Standards reported on the preliminary status of Panel 3, whose charge is to assess international competition and cooperation. Panel 3 had circulated a questionnaire worldwide to ascertain the types and styles of research being conducted abroad. Its primary findings are that the technologically advanced countries such as Japan and Germany (1) show patterns of strong government support of cooperative consortia including industry, and support of long term funding; and (2) also show a marked concentration on small, strongly led programs, which seem to have no analog in the United States. Reflecting Chynoweth's previous remarks, Schwartz commented on the United States' failure to harvest results of international MSE research, using fibers for metal-matrix composites as an example. Fibers for metal-matrix composites were first reported in Soviet literature, then picked up and put into use by Japan - from whom the United States finally discovered the advance. Said Schwartz, "We cannot afford to be third in harvesting."

Schwartz also noted that the participation of U.S. scientists in international congresses has been decreasing over the past 20 years relative to other foreign nationals. His contention was that "being there" is crucial to the technical interchange with

Continued 
foreign competitors and that the United States has been trending in the wrong direction.

An answer to the MIГI laboratories of Japan and the Max Planck Society or Frauenhofer Gesellschaft laboratories of Germany is, said Schwartz, partly contained in the relaxation of antitrust laws in the U.S. (begun with the 1984 National Cooperative Research Act) and resulting in such multilateral consortia as MCC and SRC.

Schwartz's concluding remarks concerned the proportion of U.S. research and development money in materials which can be described as defense oriented. Though total budgets have increased, the proportion of defense-oriented research has outstripped the nondefense area and, said Schwartz, defense R\&D "does not substitute for nondefense R\&D."

\section{Panel 4-Research Resources in MSE}

Panel 4's preliminary findings concerning the resources available to MSE were presented by Terry Loucks of the Norton Company. Panel 4 has focused on the statistical data, which is available in great quantities concerning the funding of research and the existing human and facility resources at universities, government laboratories, and industry. The well-known difficulty in ascertaining which portions of a research budget pertain to materials research when these are not specifically named in budgetary reports was described.

The panel studied the current environment of the individual investigator, and the balance between large numbers of small awards and a small number of large grants to large facilities. Loucks pointed out that the MSE field is in a growth mode "not measured by the numbers of university graduates, but by participation in MRS and March APS meetings which reflect actual participation in the field."

The kinds of recommendations Panel 4 may generate, said Loucks, include the following:

- Follow the Seitz-Eastman recommendations regarding large facilities and seek international cooperation in that regard.
- Continue implementation of the PackardBromley Report recommendations and those of the report of the President's Commission on Industrial Competitiveness (the "Young" report).

- Launch a new "strategic manufacturing initiative" around four or more supercenters dedicated to MSE of nanofacturing (the control of manufacturing, synthesis, and processing at the molecular level). Such a supercenter might be a "repainted national laboratory." Four such nanofacturing supercenters were suggested: electronic materials and processing, structural materials, nanofacturing equipment, and molecular imaging and surface science (nanoscale vision).

- Establish a monitoring process to check on and encourage research on strategic materials (a civilian analog to DARPA).

- Assess how reasonable it is to devote only $1.5 \%$ of the federal $R \& D$ budget to materials research.

\section{Panel 5-Education in MSE}

The final progress report, that of Panel 5 on MSE education, was given by Mel Bernstein of Carnegie Mellon University. Panel 5 is studying four aspects of education in MSE - the prior, current, and projected MSE population; undergraduate education; graduate education and graduate research in MSE; and the continuing education of researchers who have left the university.

Regarding the first aspect (the prior, current, and projected MSE population), Bernstein cited the difficulty in defining which researchers or university graduates are in materials science. Beyond a basic core of disciplines associated with materials science, the field gets very large and includes virtually all the engineering disciplines. Initial conclusions are (1) that although emphases are shifting, the total number of individuals involved in these disciplines is not rising, and (2) that the interest in materials at the high school level is not high and is not rising.

In undergraduate education, the second area of concern to the panel, the conclusions were (1) that the best programs emphasize the fundamentals in the various materials areas and the applications of those fundamentals to practice, (2) that courses best reside in accredited materials departments, and (3) that an integrated materials core curriculum with the focus on particular specialties such as electronic materials, ceramics, etc., should be developed.

The relationship between MSE and physics, chemistry, engineering, etc. needs clarification; and a possible solution, said Bernstein, is a serious exchange of courses among departments representing those disciplines. The curricula, he continued, should emphasize the interdisciplinary nature of MSE, particularly in polymers, electronic materials, and magnetic materials, which are now weak.

In the third area of concern, graduate education and graduate research in MSE, the panel found that opportunities for research are far too broad to be accommodated solely in a single department. Bernstein suggested that the unique aspects of MSE, (i.e., the tetrahedron of synthesis/processing, performance, properties, and structure) be blended into the other disciplines of physics, chemistry and so forth. A possible response to the growing thrust in MSE could be the creation of schools of materials science and engineering at research universities in order to build around an MSE core.

The fourth area of concern, the continuing education of researchers who have left the university, is still under assessment by the panel. However, said Bernstein, continuing education seems to be more and more relevant because of the rapid changes in the MSE field.

Editor's Note: See the MRS BULLETIN, Vol. XI No. 6 (1986) p. 41, for a complete list of MSE Study members. Addresses for the panel chairmen are listed in the BULLETIN, Vol. XII No. 1 (1987), p. 75-76. The correct address for Panel 3 chairman L.H. Schwartz is: L.H. Schwartz, Director, Institute for Materials Science and Engineering, National Bureau of Standards, Building 223, Room B309, Gaithersburg, MD 20899; telephone (301) 975-5658.

\title{
Do You Have An Opinion?
}

\author{
The MRS BULLETIN wants your comments
}

and views on issues affecting materials research.

Send your comments to:

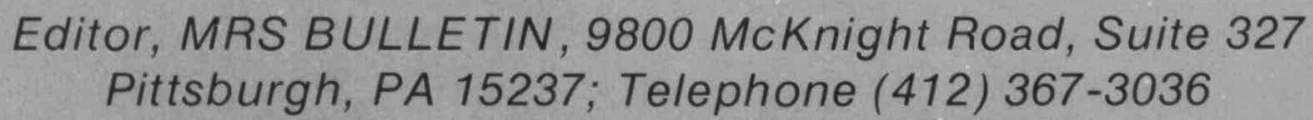

